\title{
Protein-assisted conjugated polymer microarray: Fabrication and sensing applications
}

\author{
LÜ FengTing*, FENG XuLi, LIU LiBing \& WANG Shu* \\ Key Laboratory of Organic Solids, Institute of Chemistry, Chinese Academy of Sciences, Beijing 100190, China
}

Received March 27, 2013; accepted May 15, 2013; published online August 13, 2013

\begin{abstract}
A new strategy is performed to fabricate conjugated polymer microarray with the assistance of protein in this work. The water-soluble cationic conjugated polymer employed in the present work is capable of absorbing light at $510 \mathrm{~nm}$, which makes it compatible with a variety of commercial microarray scanners. It is demonstrated that the protein-assisted conjugated polymer microarray exhibits higher fluorescence signal and better stability in comparison with the case without protein. The conjugated polymer microarray can be used for sensitive detection of picric acid (PA). A major advantage of our approach is its simplicity and chemical linking is not required between the conjugated polymer and microarray substrate. Considering the simplicity of the preparation of the conjugated polymer microarray, it is anticipated that novel sensing platforms will be constructed by employing this versatile method.
\end{abstract}

conjugated polymers, microarray, picric acid, sensors

Citation: $\quad$ Lü F T, Feng X L, Liu L B, et al. Protein-assisted conjugated polymer microarray: Fabrication and sensing applications. Chin Sci Bull, 2013, 58: 4039-4044, doi: 10.1007/s11434-013-6025-6

Microarray techniques have played an increasingly important role in modern biology and medicine due to their high-throughput and multiplexed detection in a single experiment [1]. The immobilization of biomolecules such as oligonucleotides, peptides, and proteins in microarray formats with parallel detection have been extensively developed and become ideal tools for the advancement of genomics and proteomics. The microarray-based bioassay has proven to be a time- and material-saving method [2-5]. However, in most cases, this method relies on fluorescent tagging of the analytes for detection. Since the sensory signal is proportional to the number of the fluorescent dyelabeled analytes, it cannot provide sufficiently sensitive detection when the concentration of target is low. Several attempts have been made to increase the sensitivity of the fluorescent readout of detection, such as label-free detection strategy, introducing quantum dot, or multifunctional nanoparticles to enhance the fluorescent signal [6,7]. An alternative way is to employ conjugated polymers as signal-trans-

*Corresponding authors (email: lvft@iccas.ac.cn; wangshu@iccas.ac.cn) ducing elements. In comparison to small molecule counterparts, conjugated polymers exhibit exceptional signal amplification due to the delocalization and rapid diffusion of excitons throughout the individual polymer chains [8]. The applications of fluorescent conjugated polymers in biosensor field have undergone enormous growth in recent years, which has been driven by the use of conjugated polyelectrolytes (CPEs) [9-17]. By virtue of the electrostatic attraction between a cationic conjugated polymer and negatively charged DNA, conjugated polymers have been successfully employed as signal transducer in DNA microarray $[11,14,15]$.

The Leclerc group [18] extended the well-defined fluorescence chain reaction (FCR) amplification mechanism in homogeneous aqueous to microarray-based multiplex detection. Following the similar strategy, polythiophene/DNA aptamer microarray was used to identify protein targets with high sensitivity and selectivity [19]. Fluorescent images of the spotted slide after hybridization with target DNA or protein were taken with a customized microarray fluorescence scanner which integrated a blue-violet diode laser source excitation of the cationic conjugated polymer at 408 
nm. Similar studies were carried out by Inganäs and coworkers [20], and they fabricated DNA microarray by adsorbing cholesterol-tagged DNA on a surface energy patterned substrate. Kim et al. [21-23] constructed a signal amplifying DNA microarray by means of covalent immobilization of poly(oxadiazole-co-phenylene-co-fluorene) on a glass substrate, and then direct on-chip synthesis of oligonucleotides on the resultant thin-layer film of conjugated polymer. On the basis of DNA detection in microarray manner, Kim et al. [24,25] developed DNA modified polydiacetylene (PDA) microarrays for selective detection of potassium and mercury ions. Bazan et al. [26,27] designed a cationic, water-soluble poly[9,9'-bis- $\left(6^{\prime \prime}-N, N, N\right.$ trimethylanmmon ium) hexylfluorene-co-alt-4,7-(2,1,3benzothiadi azole) dibromide (PFBT), which is capable of absorbing light at $488 \mathrm{~nm}$ compatible with a variety of commercial microarray scanners.

Although significant progress has been made in the application of conjugated polymers as signal amplifier for microarray-based sensing system, widespread incorporation of conjugated polymers into microarray assays has not been accomplished thus far, primarily because the aforementioned conjugated polymers cannot be excited at wavelength that commercial microarray scanners use. Very recently, we developed polyfluorene microarrays for sensitive, selective copper ions detection [28]. Polyfluorene derivatives were covalently immobilized on an epoxy-terminated monolayer on glass surface which imparts long-term stability of the polymer chains. In this contribution, we present our recent development of conjugated polymer microarray with the assistance of protein, which allows for sensitive detection of picric acid (PA) with the commercial available microarray scanner. In our design strategy, protein functions as a promoter to increase the amount and the stability of cationic conjugated polymers on the substrate via electrostatic association and hydrophobic interactions, as well as anchor unit binding to the surface, where proteins are chemically immobilized on glass surface through the chemical reaction between amino groups of proteins and epoxy groups on the glass surface.

\section{Experimental}

\subsection{Materials and apparatus}

All chemicals were purchased from Aldrich Chemical Company or Alfa-Aesar and used as received. Goat-antihuman IgG was purchased from Beijing XinJingKe Biotechnology Company. Compound 1 (2,7-dibromo-9,9bis( $N$-biotinhexyl)- $9 H$-fluorene), 2 (2,7-di(4',4',5',5'-tetramethyl-1', $3^{\prime}, 2^{\prime}$-dioxaborolane)-9,9-bis(6'-bromohexyl)-9Hfluorene) and 3 (2,5-bis(6'-bromohexyl)-3,6-bis(4'-bromophenyl)pyrrolo[3,4-c]pyrrole-1,4(2H,5H)-dione) were prepared according to the reported procedures [29]. The gel permeation chromatography (GPC) measurement was per- formed on a Water-410 system against polystyrene standards with tetrahydrofuran (THF) as eluent. ${ }^{1} \mathrm{H}$ NMR was collected on a $400 \mathrm{MHz}$ AC Bruker spectrometer. Fluorescence measurements were performed at room temperature using a Hitachi F-4500 fluorometer equipped with a Xenon lamp excitation source. The slit width and PMT voltages of the measurements were $5 \mathrm{~nm}$ and $700 \mathrm{~V}$, respectively. The UV-Vis absorption spectra were taken on a JASCO V-550 spectrophotometer. Microarrays were prepared by personalArrayer 16 microarray spotter (CapitalBio corporation). The dried microarrays were scanned using a LuxScan-10 K/A dual-channel laser microarray scanner (CapitalBio), equipped with a $532 \mathrm{~nm}$ laser with $10 \mu \mathrm{m}$ pixel resolution. The excitation power and PMT were set to 80 , and 800 , respectively. Microarray feature intensity data were acquired in a form compatible with Microsoft Excel. LuxScan 3.0 software (CapitalBio Instruments) is used to extract the net median pixel intensities for individual features from the digital images produced by the LuxScan-10K/A scanner. The net intensity value for each spot by subtracting background value from signal intensity value, and then averaged the signal net intensity values of 20 spots.

\subsection{Synthesis of PFDPN-B}

To a mixture of compound 1 (30 mg, $0.03 \mathrm{mmol}$ ), compound 2 (112 mg, $0.15 \mathrm{mmol}$ ), compound $3(93 \mathrm{mg}, 0.12$ $\mathrm{mmol})$ and $2.0 \mathrm{~mol} / \mathrm{L} \mathrm{K}_{2} \mathrm{CO}_{3}(2 \mathrm{~mL})$ in THF $(8 \mathrm{~mL}), \mathrm{PdCl}_{2}$ (dppf) (dppf=1,1'-bis(diphen ylphosphine)-ferrocene) was added $\quad \mathrm{PdCl}_{2}(\mathrm{dppf}) \quad\left(\mathrm{dppf}=1,1^{\prime}\right.$-bis(diphenylphosphine)ferrocene) under nitrogen atmosphere. The resulting mixture was stirred at $80^{\circ} \mathrm{C}$ for $48 \mathrm{~h}$. After cooling down to room temperature, the solvent was removed and the mixture was extracted with chloroform. The organic layer was dried over anhydrous $\mathrm{MgSO}_{4}$, and precipitated into acetone. The crude polymer $\mathbf{4}$ were purified by precipitation from chloroform into acetone twice and dried under vacuum to give a red orange solid (15\% yield). ${ }^{1} \mathrm{H}$ NMR $\left(400 \mathrm{MHz}, \mathrm{CDCl}_{3}\right)$ $\delta=8.35-7.44(\mathrm{~m}, 24 \mathrm{H}), 5.89-5.54(\mathrm{~m}, 2 \mathrm{H}), 4.93(\mathrm{br}, 4 \mathrm{H})$, $3.88(\mathrm{~s}, 8 \mathrm{H}), 3.39(\mathrm{t}, 14 \mathrm{H}), 2.08(\mathrm{~s}, 10 \mathrm{H}), 1.76(\mathrm{~d}, 18 \mathrm{H})$, $1.40(\mathrm{~d}, 12 \mathrm{H}), 1.25(\mathrm{~s}, 30 \mathrm{H}), 0.81(\mathrm{~d}, 12 \mathrm{H})$. The polymer 4 was treated with trimethylamine solution in THF for $24 \mathrm{~h}$ to obtain PFDPN-B (95\% yield). ${ }^{1} \mathrm{H}$ NMR $\left(400 \mathrm{MHz}, \mathrm{CD}_{3} \mathrm{OD}\right)$ $\delta=8.44(\mathrm{~s}, 2 \mathrm{H}), 8.17-7.20(\mathrm{~m}, 24 \mathrm{H}), 5.18(\mathrm{~s}, 2 \mathrm{H})$, 4.40-4.08 (m, 4H), 3.92 (br, 8H), 3.53 (br, 20H), 3.28 (s, $54 \mathrm{H}), 3.14(\mathrm{~d}, 28 \mathrm{H}), 2.97(\mathrm{~s}, 32 \mathrm{H}), 2.63(\mathrm{~d}, 4 \mathrm{H}), 2.50(\mathrm{~s}$, $4 \mathrm{H}), 2.28(\mathrm{~d}, 8 \mathrm{H}), 2.20(\mathrm{~s}, 8 \mathrm{H}), 2.07-1.43(\mathrm{~m}, 46 \mathrm{H}), 1.21(\mathrm{~d}$, $40 \mathrm{H}), 0.85$ (d, 6H), 0.69 (s, 4H).

\subsection{General protocol for microarray construction and picric acid detection}

Spot solution was prepared before the microarray construction (components: $10 \mu \mathrm{L} 1 \mathrm{mg} / \mathrm{mL}$ goat-anti-human IgG in PBS containing $30 \%$ (v/v) glycerol, $10 \mu \mathrm{L} 5 \mu \mathrm{mol} / \mathrm{L}$ 
PFDPN-B solution, and $1 \mu \mathrm{L} 0.2 \%$ Triton X-100). The spot solution was transferred to a 384-well source plate immediately before spotting. Spotting was performed using the personalArrayer 16 microarray spotter on epoxy-terminated slides (CapitalBio OPEpoxySlideTM) in room temperature with $60 \%$ humidity. After spotting, microarrays were dried by placing the spotted slides in a vacuum dessicator at $37^{\circ} \mathrm{C}$ for $12 \mathrm{~h}$ according to the manufacturer's suggestion. The chemical reaction between amino groups of proteins and epoxy groups is employed to immobilize proteins on the glass surface, which is a well-developed procedure to fabricate proteins microarray.

\subsection{Picric acid detection}

PFDPN-B/IgG microarray was incubated with $10 \mu \mathrm{L}$ analytes at room temperature for $30 \mathrm{~min}$ in a humid chamber, and then removing the analytes with pipette from the slide. After drying, the images of the microarray were subsequently scanned.

\section{Results and discussion}

Scheme 1 depicts the synthetic route of poly[9,9'-bis $\left(6^{\prime \prime}-N\right.$, $N, N$-trimethylanmmonium)hexyl fluorene-co-alt-2,5-bis(6"$N, N, N$-trimethylanmmonium)hexylpyrrolo[3,4-c]pyrrole-1, $4(2 H, 5 H)$-dione] (PFDPN-B). Polymerization of monomer $\mathbf{1}$ and $\mathbf{3}$ with diboronic acid ester $\mathbf{2}$ via Suzuki coupling affords precursor polymer (4) by adopting a modified literature method [18]. The gel permeation chromatography (GPC) analyses show that the weight-average molecular weight $\left(M_{\mathrm{w}}\right)$ and number-average molecular weight $\left(M_{\mathrm{n}}\right)$ of 4 are 17470 and 10810 , respectively, with the polydispersity index (PDI) of 1.61. Polymer 4 reacts with trimethylamine to afford water-soluble cationic PFDPN-B. The fluorescence quantum yield of PFDPN-B is measured to be $6.6 \%$ in water with quinine sulfate in $0.1 \mathrm{~mol} / \mathrm{L} \mathrm{H}_{2} \mathrm{SO}_{4}$ as the standard. UV-Vis and emission spectra of PFDPN-B in aqueous solution are presented in Figure 1. The PFDPN-B exhibits two distinguished absorption peaks at 340 and 510 $\mathrm{nm}$, and maximum fluorescence emission peak at $580 \mathrm{~nm}$,

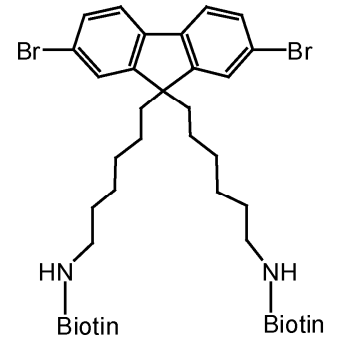

1

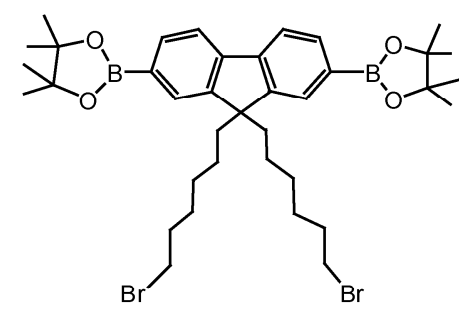

2

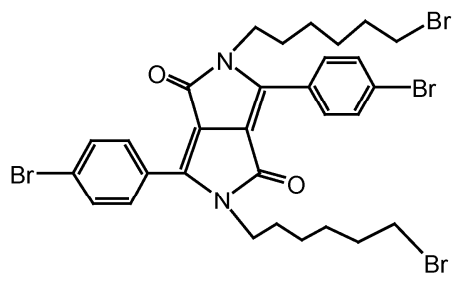

3

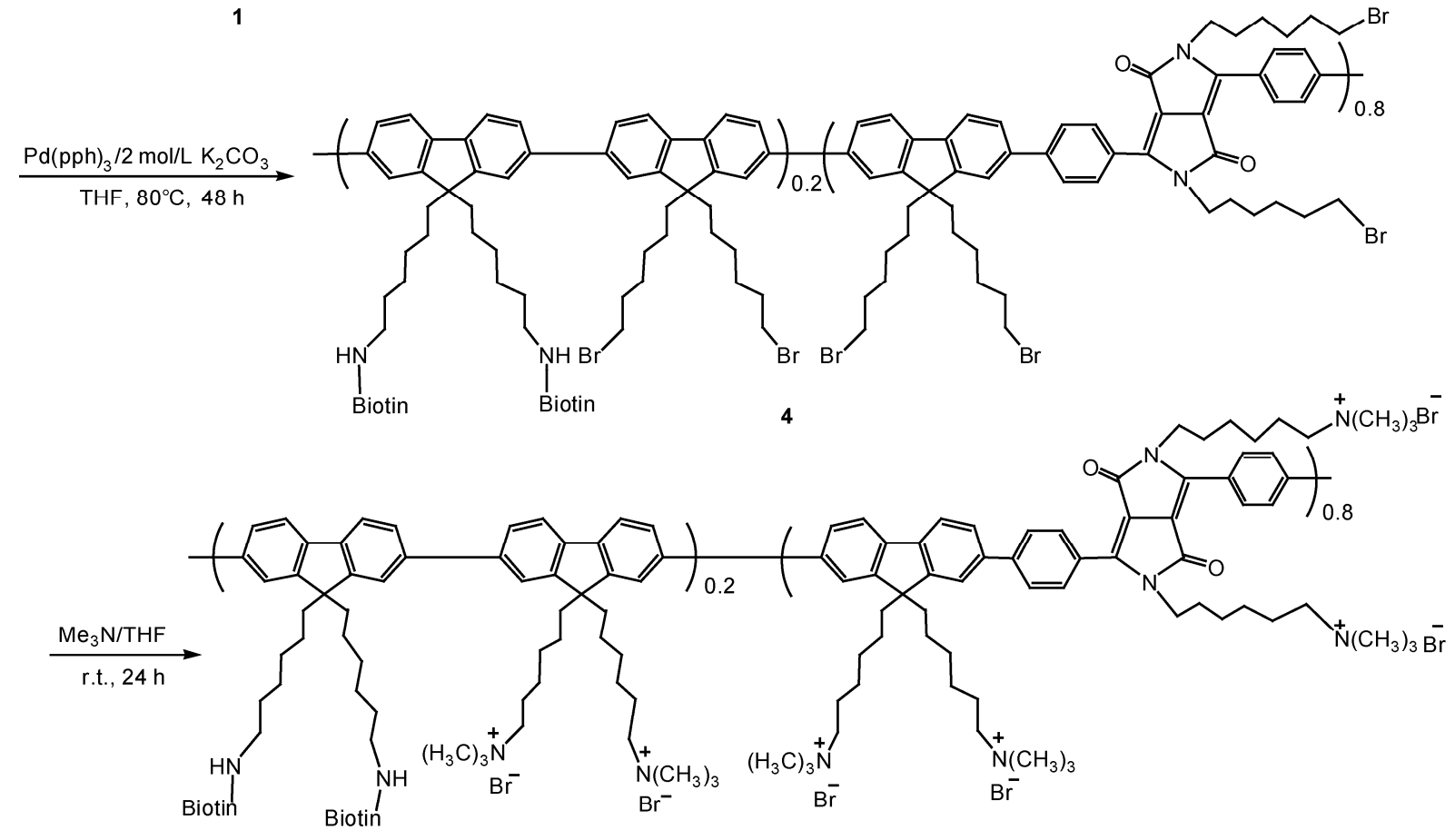

PFDPN-B

Scheme 1 Synthetic route for cationic conjugated polymer PFDPN-B. 


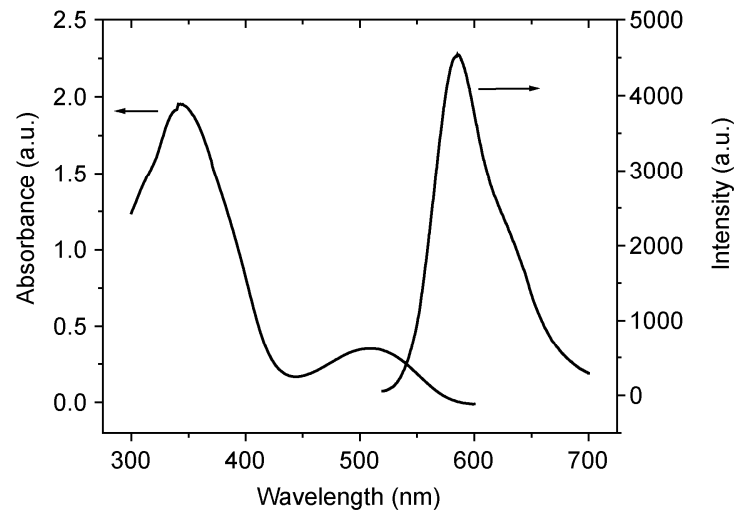

Figure 1 UV-vis absorption and emission spectra of PFDPN-B in aqueous solution. The excitation wavelength for emission spectra is $510 \mathrm{~nm}$.

which makes it compatible with standard microarray scanner instrumentation with 488 and $532 \mathrm{~nm}$ excitation sources.

Goat-anti-human antibody IgG, PFDPN-B and the mixture of IgG and PFDPN-B were respectively spotted on epoxy-modified glass substrate under identical condition. The corresponding microarrays were examined with fluorescence microarray scanner after rinsing and drying. The representative images are shown in Figure 2. The diameter of each spot is ca. $150 \mu \mathrm{m}$ with a $500 \mu \mathrm{m}$ horizontal and vertical pitch (pitch $=$ center to center spacing of spots). The very weak green signal from the microarray where only IgG was immobilized was due to the light scattering in the fluorescent channel of the printed spots (Figure 2(a)). A weak fluorescent was detected on conjugated polymer microarray (Figure 2(b)), suggesting a relatively low binding efficiency between PFDPN-B and epoxy terminated substrate surface. When comparing Figure 2(a) and 2(b) with the distinct green fluorescence on a substrate spotted with mixture of PFDPN-B and IgG (Figure 2(c)), it is clear that immobilization mediated through interactions between $\mathrm{IgG}$ and PFDPN-B is more effective, and results in better array quality and stability. We also used a conjugated polymer with a similar chemical structure as PFDPN-B but without biotin moieties to fabricate the microarray. Compared with PFDPN-B/IgG microarray, much lower fluorescent signal were obtained, even 10 times dense concentration of polymer without biotin moieties was used, which indicated that the addition of the biotin moieties enhances hydrophobic

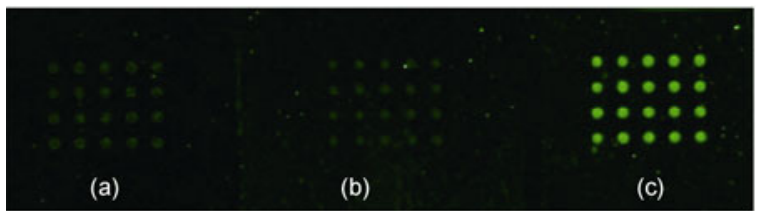

Figure 2 Scanned microarray images of spotted slides with goat-antihuman IgG only (a), PFDPN-B only (b), and mixture of goat-anti-human IgG and PFDPN-B (c). The images were obtained by scanning microarrays through the $\mathrm{Cy} 3$ channel. interactions between conjugated polymer and antibody, and therefore increase the stability of PFDPN-B/IgG microarray.

As a proof-of-concept application of the novel PFDPN$\mathbf{B} / \mathrm{IgG}$ microarray, we investigated the selective detection of 2, 4, 6-trinitrophenol (picric acid) using this microarray. PA is a widely used reagent in pharmaceutical, dye industries, as well as in the manufacture of explosives and rocket fuels, which makes it an important environmental pollutant. Sensitive detection of PA has attracted more concern recently [30,31]. PA is an electron-deficient nitroaromatics that can quench the fluorescence emission of the microarray via electron donor-acceptor interaction [8]. A representative image of PFDPN-B/IgG microarray treated with $1 \mathrm{mmol} / \mathrm{L}$ $\mathrm{PA}$ and the corresponding fluorescence signal intensity are shown in Figure 3. The emission of the microarray is strongly quenched by PA with a $73 \%$ quenching efficiency. The quenching efficiency is calculated with the following equation:

$$
\text { Quenching efficiency }=\left(I_{0}-I\right) / I_{0} \times 100 \% \text {, }
$$

where $I_{0}$ and $I$ stand for the fluorescence intensity of microarray in the absence and presence of the quencher, respectively.

Figure 4(a) depicts quenching efficiency of various PA concentrations to PFDPN-B/IgG microarray. It is noted that even $10 \mu \mathrm{mol} / \mathrm{L}$ PA could be easily detected with a $15 \%$ quenching efficiency. The response time of PFDPN-B/IgG microarray to PA was also studied by monitoring the fluorescence intensity of the microarray as a function of incubation time. As shown in Figure 4(b), fluorescence intensity of the microarray is quenched by $50 \%$ after 5 min incubation with $1 \mathrm{mmol} / \mathrm{L} \mathrm{PA}$, and it takes approximate $30 \mathrm{~min}$ to get equilibrium.
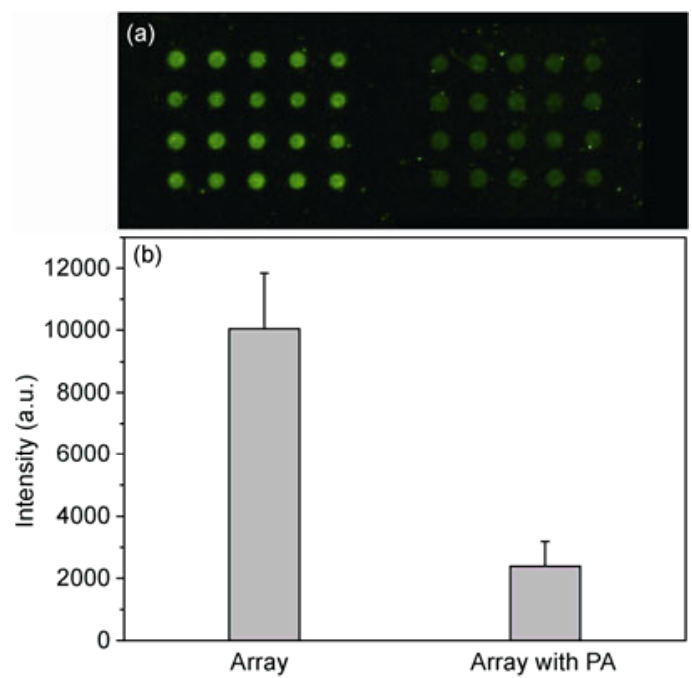

Figure 3 Scanned images of PFDPN-B/IgG microarray and after adding $1 \mathrm{mmol} / \mathrm{L}$ PA incubated at room temperature for $30 \mathrm{~min}$ (a), and the corresponding fluorescence signal intensity of each microarray (b). Fluorescence values were calculated as the local background corrected mean of all pixels, and error bars represent the spot-to-spot standard deviation. 

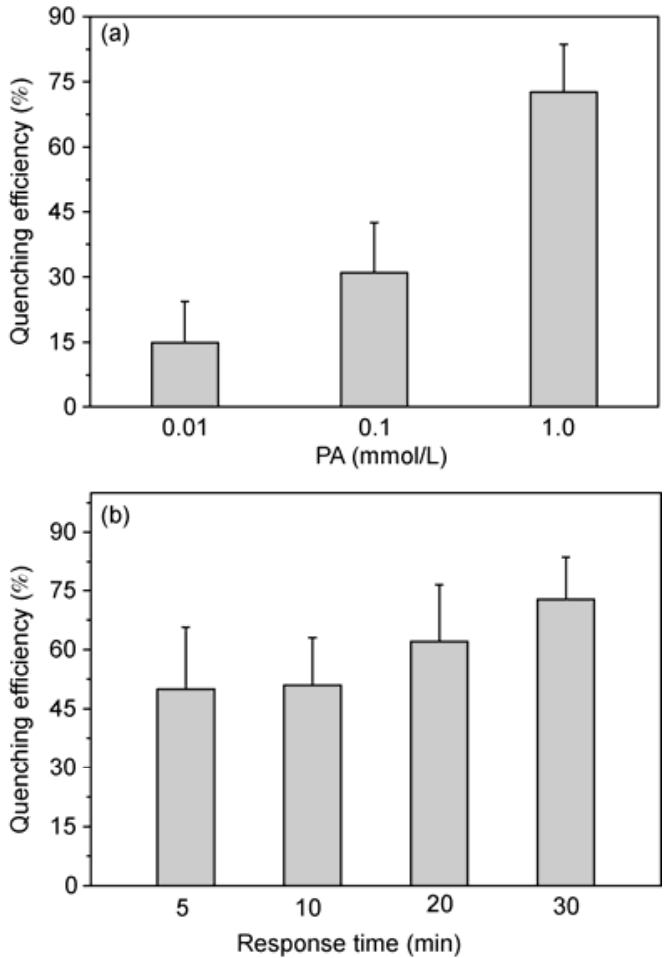

Figure 4 (a) The response of PFDPN-B/IgG microarray to different concentrations of PA; (b) the response time of PFDPN-B/IgG microarray to $1 \mathrm{mmol} / \mathrm{L} \mathrm{PA}$.

To show the selectivity of the PFDPN-B/IgG microarray for PA detection, the response of the microarray to 2, 4-dinitrophenol (DNP) and p-nitrophenol (NP) were also performed. As shown in Figure 5, DNP exhibits 45\% quenching efficiency and only $4 \%$ quenching efficiency is obtained for NP. The results are easily understood by considering the degree of the electron deficiency of the aromatics. And the results are also quite in agreement with the assumption that the quenching originates from the electron transfer from polymer backbone to electron-deficient nitroaromatics. More nitro-groups in the aromatic compound show stronger affinity to the electron from the fluorophore moieties, and thereby show more quenching efficiency.

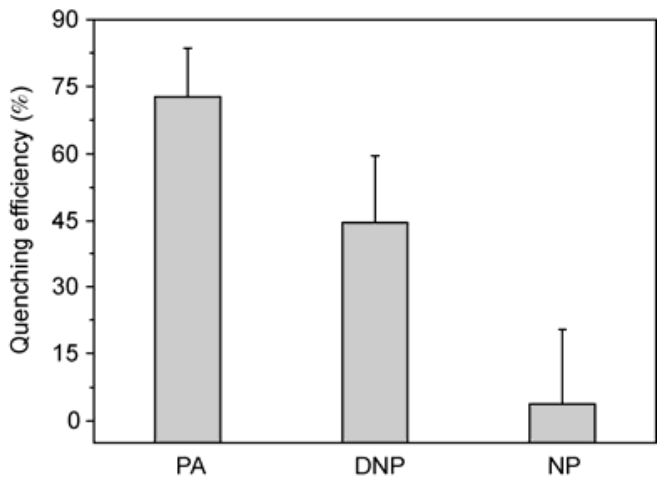

Figure 5 Quenching efficiencies of $1 \mathrm{mmol} / \mathrm{L}$ different nitroaromatic compounds to PFDPN-B/IgG microarray.

\section{Conclusions}

In summary, we developed a novel strategy for fabricating protein-assisted conjugated polymer microarray. The protein functions as a promoter to increase the amount and the stability of cationic conjugated polymers on the substrate through electrostatic and hydrophobic interactions, which imparts the PFDPN-B/IgG microarray higher signal intensity and more stability. A major advantage of our approach is its simplicity and chemical linking is not required between the conjugated polymer and microarray substrate. It is expected that this fabrication approach can be easily incorporate with other water-soluble cationic conjugated polymers. The PFDPN-B/IgG microarray was employed to selectively detect PA over DNP and NP through the quenching of microarray fluorescence that attributes to the electron-deficient nature of PA. Future efforts can be directed towards tethering receptors on the conjugated polymer microarray for biomedical and biotechnological studies.

This work was supported by the National Natural Science Foundation of China $(21203213,21021091)$ and the National Basic Research Program of China (2011CB808400, 2013CB932800).

1 Kumar A, Goel G, Fehrencach E, et al. Microarrays: The technology, analysis and application. Eng Life Sci, 2005, 5: 215-222

2 Heller M J. DNA microarray technology: Devices, systems, and applications. Annu Rev Biomed Eng, 2002, 4: 129-153

3 Dirk W, Pascal J, Christof N, et al. Applications of protein biochips in biomedical and biotechnological research. Angew Chem Int Ed, 2009, 48: 7744-7751

4 Sassolas A, Leca-Bouvier B D, Blum L J. DNA biosensors and microarrays. Chem Rev, 2008, 108: 109-139

5 Yoo S M, Choi J Y, Yun J K, et al. DNA microarray-based identification of bacterial and fungal pathogens in bloodstream infections. Mol Cell Probes, 2010, 24: 44-52

6 Giljohann D A, Seferos D S, Daniel W L, et al. Gold nanoparticles for biology and medicine. Angew Chem Int Ed, 2010, 49: 3280-3294

7 Rousserie G, Sukhanova A, Even-Desrumeaux K, et al. Semiconductor quantum dots for multiplexed bio-detection on solid-state microarrays. Crit Rev Oncol Hemat, 2010, 74: 1-15

8 Thomas S W, Joly G D, Swager T M. Chemical sensors based on amplifying fluorescent conjugated polymers. Chem Rev, 2007, 107: 1339-1386

9 Duan X R, Liu L B, Wang S, et al. Cationic conjugated polymers for optical detection of DNA methylation lesions and single nucleotide polymorphisms. Acc Chem Res, 2009, 43: 260-270

10 Zhu C L, Liu L B, Wang S, et al. Water-soluble conjugated polymers for imaging, diagnosis, and therapy. Chem Rev, 2012, 112: 46874735

11 Ho H A, Najari A, Leclerc M. Optical detection of DNA and proteins moth cationic polythiophenes. Acc Chem Res, 2008, 41: 168-178

12 Jiang H, Taranekar P, Schanze K S, et al. Conjugated polyelectrolytes: Synthesis, photophysics, and applications. Angew Chem Int Ed, 2009, 48: 4300-4316

13 Pecher J, Mecking S. Nanoparticles of conjugated polymers. Chem Rev, 2010, 110: 6260-6279

14 Duarte A, Pu K Y, Liu B, et al. Recent advances in conjugated polyelectrolytes for emerging optoelectronic applications. Chem Mater, 2011, 23: 501-515

15 Lee K, Povlich L K, Kim J. Recent advances in fluorescent and colorimetric conjugated polymer-based biosensors. Analyst, 2010, 
135: 2179-2189

16 Wen Q, Tang H, Wang S, et al. Synthesis and characterization of oligofluorene nanoparticles for cell imaging. Acta Chim Sin, 2012, 70: 2137-2143

17 An L L, Liu L B, Wang S. Cationic conjugated polymers for homogeneous and sensitive fluorescence detection of hyaluronidase. Sci China Chem, 2009, 52: 827-832

18 Najari A, Ho H A, Leclerc M, et al. Reagentless ultrasensitive specific DNA array detection based on responsive polymeric biochips. Anal Chem, 2006, 78: 7896-7899

19 Aberem M B, Najari A, Leclerc M, et al. Protein detecting arrays based on cationic polythiophene-DNA-aptamer complexes. Adv Mater, 2006, 18: 2703-2707

20 Wigenius J A, Magnusson K, Inganas O, et al. DNA chips with conjugated polyelectrolytes in resonance energy transfer mode. Langmuir, 2009, 26: 3753-3759

21 Lee K, Rouillard J M, Kim J, et al. Signal-amplifying conjugated polymer-DNA hybrid chips. Angew Chem Int Ed, 2007, 46: 46674670

22 Lee K, Maisel K, Kim J, et al. Sensitive and selective label-free DNA detection by conjugated polymer-based microarrays and intercalating dye. Chem Mater, 2008, 20: 2848-2850

23 Lee K, Rouillard J M, Kim J, et al. Conjugated polymers combined with a molecular beacon for label-free and self-signal-amplifying DNA microarrays. Adv Funct Mater, 2009, 19: 3317-3325
24 Lee J, Kim H, Kim J. Polydiacetylene liposome arrays for selective potassium detection. J Am Chem Soc, 2008, 130: 5010-5011

25 Lee J, Jun H, Kim J. Polydiacetylene-liposome microarrays for selective and sensitive mercury (II) detection. Adv Mater, 2009, 21: 36743677

26 Liu B, Bazan G C. Methods for strand-specific DNA detection with cationic conjugated polymers suitable for incorporation into DNA chips and microarrays. Proc Natl Acad Sci USA, 2005, 102: 589593

27 Sun C J, Gaylord B S, Bazan G C, et al. Application of cationic conjugated polymers in microarrays using label-free DNA targets. Nat Protoc, 2007, 2: 2148-2151

28 Lv F T, Feng X L, Wang S, et al. Development of film sensors based on conjugated polymers for copper (II) ion detection. Adv Funct Mater, 2011, 21: 845-850

29 He F, Liu L B, Li L D. Water-soluble conjugated polymers for amplified fluorescence detection of template-independent DNA elongation catalyzed by polymerase. Adv Funct Mater, 2011, 21: 31433149

30 Pimienta V, Etchenique R, Buhse T. On the origin of electrochemical oscillations in the picric acid/ctab two-phase system. J Phys Chem A, 2001, 105: 10037-10044

31 Sohn H, Calhoun R M, Trogler W C. Detection of TNT and picric acid on surfaces and in seawater by using photoluminescent polysiloles. Angew Chem Int Ed, 2001, 40: 2104-2105

Open Access This article is distributed under the terms of the Creative Commons Attribution License which permits any use, distribution, and reproduction in any medium, provided the original author(s) and source are credited. 